\title{
The impact of coastal orography on profile wind
}

\author{
Abderrahim Moujane ${ }^{1,2} *$, Abderrahim Bentamy ${ }^{3}$, Mohammed Chagdali ${ }^{4}$, Soumia Mordane ${ }^{5}$ \\ ${ }^{1}$ National Meteorology Direction, Casablanca, Morocco \\ ${ }^{3}$ Institut Français pour la Recherche et l'Exploitation de la MER \\ 2, 4, 5 Faculty of Sciences Ben M'Sick, Casablanca, Morocco \\ *Corresponding author E-mail: abderrahim.moujane@gmail.com
}

\begin{abstract}
The quality of the speed and direction of the surface wind issued from the regional model for weather forecasting "Aire Limitée Adaptation dynamique Développement International (ALADIN)", currently operational in the National Meteorological Direction (DMN), is studied in comparison with the $10 \mathrm{~m}$ observed speed and direction from meteorological stations and with new scatterometer wind products (QuikSCAT and Blended QuikSCAT). The series of average wind speed shows that ALADIN model could correctly reproduce the wind speed in the accented winds zones as well as in areas of reduced winds either on the coast or offshore (Moujane, et al, 2011). Some differences still existing between simulations and satellite measurements can be attributed to the nature of the QuikSCAT data used in this study. In fact, this data are daily, while the results of the ALADIN model are a grid values for each three hours reduced to a daily average. The simulated winds comply well reasonably with winds of QuikSCAT and QuikSCAT BLENDED throughout the study area, although significant differences are noted in the in situ and satellite observations. ALADIN model resolution is $0.17^{\circ}$ whereas QUIKSCAT is only $0.5^{\circ}$ and the spatial resolution of QUIKSCAT BLENDED is $0.25^{\circ}$, adding to these remarks the limitations of satellite measurement near the coast obtained with a precision of $2 \mathrm{~ms}-1$. QuikSCAT face Aladin and QuikSCAT BLENDED confirm a high correlation reaching 0.9 throughout the area of study for the zonal and meridional wind component. Also, a high variability was observed with QuikSCAT compared to ALADIN and Blended during all seasons, it is of the order of 2 ms- 1 to 2.5 ms- 1 with a low difference of meridional wind which is about $0.5 \mathrm{~ms}-1$ on the area of study found mainly near the coast in the north of the area. A marked relief effect was noticed in the figures of variability, which shows well the variability induced on the wind by the Caps, the bay and the islands.
\end{abstract}

Keywords: Aladin, Blended, In-Situ, Orography, Quikscat, Wind.

\section{Introduction}

The importance of winds, wind stress and the curl of wind stress on ocean dynamics is well known, but the accuracy of the estimates and the spatial and temporal characteristics are greatly limited by the absence of observations on ocean. In the late years 1970 , the problem of accurate estimates of the wind stress in coastal areas was recognized and developed by Nelson (1977). Significant advances in understanding the structure of the wind stress and the curl wind stress is causing direct measurements of surface winds and wind stress using instrumented aircraft (D. Koraçin and al., 2004). The microwave instruments on board satellites allow the estimation of surface wind with a horizontal resolution of about $0.25^{\circ}$. Measurement errors are exposed to a filter in order to obtain reliable data from the wind. Atmospheric circulation offshore is amended by the coastal topography of the continents which generates a small-scale variability in the structures of the wind (Yi Choa and al. 2001).

Three types of atmospheric circulation characterize the Northwest African region. Southeastward Circulation associated with polar cold airflow reaching $20^{\circ} \mathrm{N}$ to $15^{\circ} \mathrm{N}$ and exceptionally $10^{\circ} \mathrm{N}$ in case of heavy downstream cold air. Such atmospheric circulation remains seasonally dependent, and the related winds and heat fluxes are generally from the westerly direction. The latter are influenced by wind and pressure field disturbances in the middle and surface boundary layers. The second circulation type is asso ciated with northeast and southeast winds (trade winds) blowing throughout the year over the Atlantic inter-tropical region. Between north and south regimes the convergence zone contributes to the northwest as well as southwest wind reinforcement, which in turn creates a strong atmosphere activity during summer. In winter, the contact between air masses brought by the north winds and warm air masses at the equator, creates the front of the trade winds which is a semi-permanent structure splitting the subtropical anticyclonic cells. Thus, a strong gradient wind exists in summer and winter over the Atlantic Ocean, and provides the remarkable phenomenon of upwelling. The third type of atmospheric circulation is associated with the southwest monsoon. These winds are caused by the difference between seasonal sea and land temperatures. The most favorable region for monsoon development is located in tropical western African area, where the weather elements are punctuated every year by the ebb and flow of the monsoon in the South-West (Moujane and al., 2011).

In the Central California Coast (CCC), the appearance of the coast (Caps, mountains etc...) induces irregularities of local winds (Winant and al,. 1988). These results are highlighted by atmospheric mesoscale models such as COAMPS (Coupled Ocean/Atmosphere Mesoscale Prediction System) on CCC, where the transition of the wind speed is highlighted in shore to the inside a narrow coastal strip of about $5 \mathrm{~km}$ where the wind grows about 10 to $20 \%$ of its offshore values (Choa and al., 2001). The cause of this increase is obviously the change land-sea in the planetary boundary layer (PBL), In fact, near the surface the internal boundary layer and the surface roughness influenced the 
wind speed, while higher up it was only influenced by the PBL scheme and the synoptic forcing (R. Floors and al., 2013). Thus, the wind COAMPS model showed expansion with improved resolution of the numerical model notably in the coast.

Also, according to the conventional view, the wind follows a progressive fall of his speed from offshore to the side, against by the MM5 numerical model (The PSU/NCAR Mesoscale Model) has shown an increase in the wind offshore to the coastline of the ocean with a sharp drop in speed on a narrow area to the coast (Koraçin al., 2004).

This leads us to consider a new approach of the wind on the coastline of the ocean and of the impact that can bring coastal topography on its speed and direction. The objective of this article is to highlight this effect of topography on wind in Moroccan coasts.

\section{Data}

\subsection{Model description}

In this study, ALADIN is used in the hydrostatic mode with a horizontal resolution of $16 \mathrm{~km}$ and an integration time of $675 \mathrm{~s}$ for the four years of simulation. The model spatial grid is interpolated at $0,08^{\circ}$ horizontal grid spacing, yielding to the horizontal map of $119 \times 160$ grid points. The number of vertical levels is 37 . ALADIN surface winds used correspond to the zonal and meridional wind forecasts at $10 \mathrm{~m}$ based on the 00:00 UTC analysis time. Data are available every 3 hours $(00 \mathrm{~h}: 00,03 \mathrm{~h}: 00,06 \mathrm{~h}: 00$, 09h:00, 12h:00, 15h:00, 18h:00, 21h:00 UTC) on regular latitudelongitude grid of $0.1^{\circ}$. The missing ALADIN wind data during the study period $(2003-2006)$ are replaced by the forecasts based on the 12:00 UTC analysis time. The former are associated with the following days 05/01/2003, 09/03/2004, 10/03/2004, 23/06/2005, 06/01/2006, 18/11/2006, 28/12 / 2006 and 30/12/2006.

\subsection{Scatterometer data}

The remotely sensed wind data are derived from the SeaWinds scatterometer on board the NASA QuikSCAT satellite (JPL, 2006). More specifically, this study uses the gridded wind fields estimated from QuikSCAT retrievals over the global ocean (Bentamy et al, 2002) and available at:

(http://cersat.ifremer.fr/fr/data/discovery/by_product_type/gridded _products/mwf_quikscat)

Their spatial resolution is $0.5^{\circ}$ in longitude and latitude, whereas three temporal resolutions are available: daily, weekly, and monthly. In this study, the daily and monthly data are used. They have been estimated from rain free QuikSCAT observations based on a geostatistical method assuming the knowledge of the spatial and temporal structure function of surface wind speed, zonal component, and meridional component.

\subsection{Blended data}

To enhance the spatial and temporal resolutions of surface wind, the remotely sensed retrievals are blended to the operational ECMWF wind analyses over the global oceans. The blending method aims to provide 6-hourly gridded wind speed, zonal component, meridional component, wind stress and the corresponding components at global scale.

The spatial resolution of the resulting wind fields is $0,25^{\circ}$ in longitude and latitude. In this study, only Blended wind estimates, covering the period 2005-2006, are available and used.

\subsection{In-situ data}

In-situ observations are derived from the DMN coastal synoptic stations (Figure 1). The main topic of using in-situ data is to provide a baseline of ALADIN and QuikSCAT comparison interpretation. These data are the hourly wind direction and wind speed, measured by the vane and anemometer instruments, $10 \mathrm{~m}$ above the ground. Wind measurements are performed at the following stations: Essaouira $\left(31^{\circ} 31^{\prime} \mathrm{N}, 9^{\circ} 47^{\prime} \mathrm{W}\right)$ Laayoune $\left(27^{\circ} 10^{\prime} \mathrm{N}\right.$, $\left.13^{\circ} 13^{\prime} \mathrm{W}\right)$ and Dakhla $\left(23^{\circ} 43^{\prime} \mathrm{N}, 15^{\circ} 56^{\prime} \mathrm{W}\right)$. More details about data may be found in (Moujane and al, 2011).

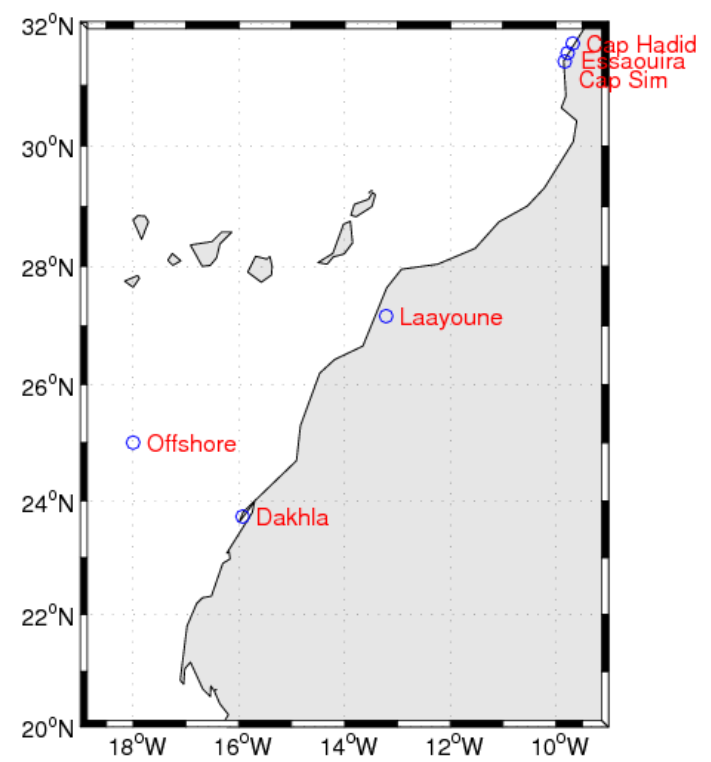

Fig.1: Northwest African Study Area. Circles Indicate Locations of ALADIN, in-Situ and Quikscat Comparisons.

\section{Spectral analysis}

\subsection{Approach and methodology.}

To characterize the temporal variability of the wind on the region and in particular variability of coastal winds and strong wind periods, wind analyzes were performed using the spectral analysis of the kinetic energy of wind.

Spectral analysis in south of Morocco, at point of Laayoune, was conducted in order to identify the frequencies characteristics of windy events. Indeed, there is no big spatial variability in spectra of the area, which will be described later. Each component of the wind, zonal and meridional, temporal average is subtracted, so as to eliminate the principal spectra component. The Fourier transform was then calculated with the zero padding method of adding zeros to the starting signal to increase the time series $\mathrm{N} \mathrm{x}$ Te, thus reducing the frequency step $\frac{1}{N x T e}$ and smooth the spectrum (where $\mathrm{N}$ is the number of samples and Te the sampling period).

Indeed, the sampling frequency calculation can cause artifacts in the aspect of the spectra, which can be solved by the method of zero padding. Then the Fourier transforms of zonal and meridional wind components were squared before being summed in order to obtain the spectrum of the kinetic energy of the wind.

\subsection{Time spectrum}

The mean wind speed in Laayoune from 01 April 2004 to 30 June 2004 is represented by a spatial average shown in Figure 2. The wind during the period 1 April 2004 to 30 June 2004 is higher or lower compared to the average which is of the order of $5.62 \mathrm{~ms}-1$. Note amplification wind between the Canary Islands under the venturi effect imposed by the juxtaposed positions islands. The figure 3 illustrate in ms-1 over a period of 91 days, the wind speed in Laayoune from 01 April 2004 to 30 June 2004.

Significant variability of wind at offshore Laayoune there with maximum exceeding $12 \mathrm{~m} / \mathrm{s}$, associated with wind directions generally north-northeast (Figure 4). 
The energy spectrum is shown below between 0 and fe/2, where fe is the sampling frequency which is 3 hours, in two different ways (Figures 5 and 7). Diurnal peaks $(\mathrm{f}=24)$ and semi diurnal $(\mathrm{f}=12)$ are directly remarkable in these figures. They represent the daily variations of the wind.

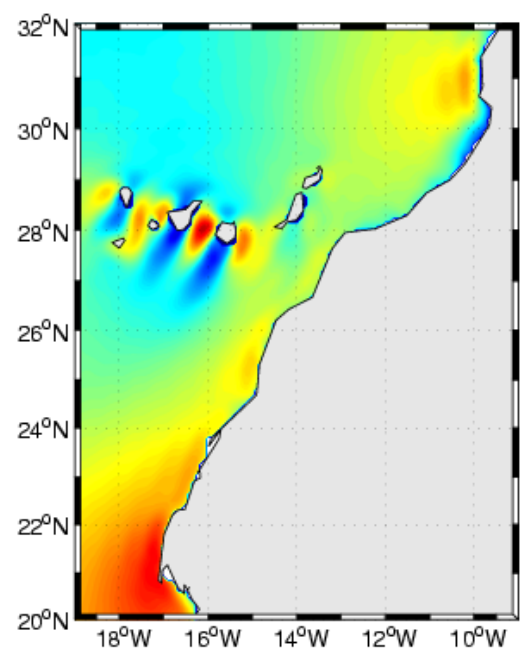

Fig. 2: The ALADIN Average Wind from 01/04/2004 To 30/06/2004.
In fact, with the spectral analysis, we could well generate strong wind periods ranging from 12 hours to a few days, reflecting the temporal expansion of the phenomenon (Figure 5 and 7).

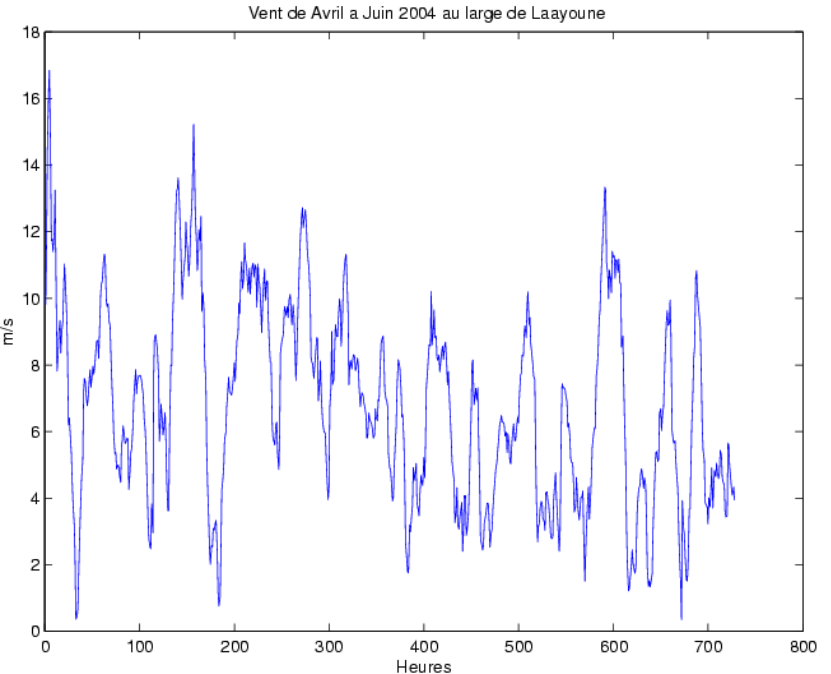

Fig. 3: Wind Velocity in M/S from 01/04/2004 To 30/06/2004 Off Laayoune.

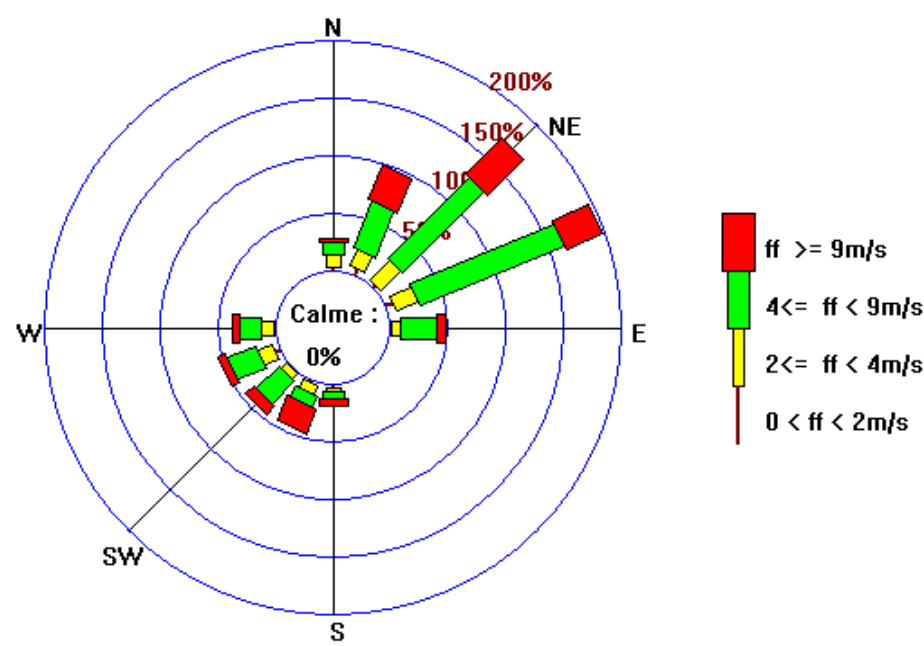

Fig. 4: Wind Direction in M/S from 01/04/2004 to 30/06/2004 Off Laayoune.

\section{Evaluation model}

ALADIN is evaluated by several applications (see www.cnrm.meteo.fr website/aladin/spip.php). In this study, we examine the ALADIN accuracy in forecasting wind fields for the years 2003 to 2006. We selected four stations representing offshore, north, central and south of coast of Moroccan south. Then we compared the data of the model results with in-situ and satellite data to corresponding points (Figure 1). The main statistics of the comparison are shown in Table 1. It is noted that the model was able to correctly reproduce the magnitude of the wind speed given by the in-situ observations and QuikSCAT measurements, the model results obtained compared with in-situ data have a correlation coefficient reaching 0,84 and have a correlation coefficient of 0.73 with the satellite measurements. In particular, there was the Dakhla station where the model gave a coefficient of correlation greater than 0.8. The lower correlations were found in Essaouira and Laayoune stations; one possible reason for this is that the model does not solve the complexity of the atmospheric dynamics at these two points. Station Laayoune is $20 \mathrm{~km}$ from the coast, which indicates the difference between the in-situ and simulated winds, about Essaouira station, the

complexity of the topography of the coast can't be resolved by model. In addition the structure of the coastal topography is quite complex, it seems that the model resolution is insufficient to resolve the complexity which is due to the shelter effect of the Canary Islands in front of Laâyoune and Cape Sim effect near Essaouira. Comparisons between simulations and observations of strong winds (Dakhla station) and observations of low winds (Essaouira station) are shown in Figure 6a and 6b. The time series of wind speed and wind direction shows that ALADIN was able to correctly reproduce the maximum and minimum wind speed periods and the persistence of the wind direction almost the entire study period (station Dakhla, Figure 6a). Some differences between simulations and measurements can be attributed to sampling differences of tri-hours observation's data and daily satellite measurements, while the model results are in grid point and average tri-hours values. The model correctly reproduces the low and strong wind speeds thus changes direction in Essaouira station (Figure. 6b). Table 1 also shows that the error between the model and the observations is much smaller than the error of the model and satellite measurements (station Essaouira and Laayoune) of time series of the wind speed. Spectral analysis of wind speed of time series also allows the evaluation of the model results. It allows in particularly obtaining the characteristics of the linear response of a system using a transfer function. The spectral power of the model simulation is shown in figure 5 and figure 7 . Diurnal peaks $(f=24)$ and semi diurnal $(f=12)$ are directly remarkable in these figures. They represent the daily variations of 
the wind. In fact, with the spectral analysis, we could well generate strong wind periods ranging from 12 hours to several days, reproducing the temporal expansion of the phenomenon in the coastal zone.

As the number of synoptic meteorological stations is small on the coast, they provide little information on the spatial structure of winds over the ocean, in recent years the scatterometer observations appear to be an excellent source of information on surface winds from the ocean. The QuikSCAT satellite provided the wind speed and direction but far from the earth, discussion remains about the accuracy of the satellite data in the absence of any measurement system.

The only actual measurements are provided by meteorological synoptic stations. Satellite measurements are missing in marine areas of $25 \mathrm{~km} 2$ of land (Larsen et al. 2001). Particular attention should be made when comparing stations and satellite data along the coast since most weather stations are located $0 \mathrm{~km}$ to $20 \mathrm{~km}$ from the coast (Moujane and al., 2011).

The comparison analysis of wind speeds from ALADIN and QuikSCAT show correlations of 0.71 and 0.73 respectively in offshore and Dakhla (Table 1). In addition, the correlation between ALADIN and in-situ data is 0.84. The lowest correlation between the model and the observation was in Essaouira location. To evaluate the simulated ocean wind, we compared the satellite data and those simulated for the study period. The simulation of the wind speed is in reasonable agreement with the speed wind of the satellite, but there are significant differences in the sampling procedures in occurrence the computation of the average, the spatial resolution $\left(0.25^{\circ}\right.$ for satellite and $16 \mathrm{~km}$ for the model $)$, and the limitations of satellite near the coast.

The analysis of the figures of simulated and measured data (Figure 8) gives an idea of the spatial agreement between the model results and satellite observations. A correlation coefficient of $37 \%$ found between QuikSCAT and Blended QuikSCAT, however we noted a coefficient correlation of 59\% between QuikSCAT and model, with a remarkable overestimation of satellite measurements over entire study area with an average standard deviation of $0.41 \mathrm{~ms}-1$ to $0.87 \mathrm{~ms}-1$ during the period from $01 / 01 / 2005$ to $31 / 12 / 2006$. The QuiKSCAT satellite and the ALADIN model also reproduce the majority of events of high wind as well as those of weak wind. Figure 9 shows evidence of spatial harmony of annual average of wind measurements and simulations on area of study with a mean difference of $1.05 \mathrm{~m} \mathrm{~s}-1$ between QuikSCAT and QuikSCAT BLENDED which is in the margin of error of the satellite which is around $2 \mathrm{~m} \mathrm{~s}-1$ (Bentamy et al., 2003), it also has a difference of 3.03 ms-1 between QuikSCAT and ALADIN which slightly exceed the margin of error of QuikSCAT, with this a correlation coefficient is $59 \%$.

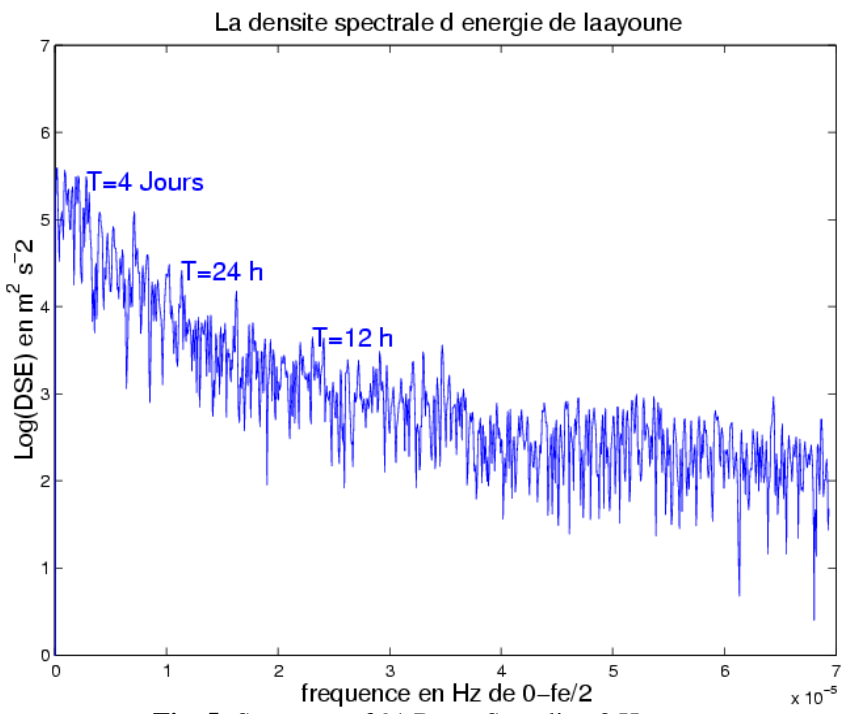

Fig. 5: Spectrum of 91 Days, Sampling 3 Hours.
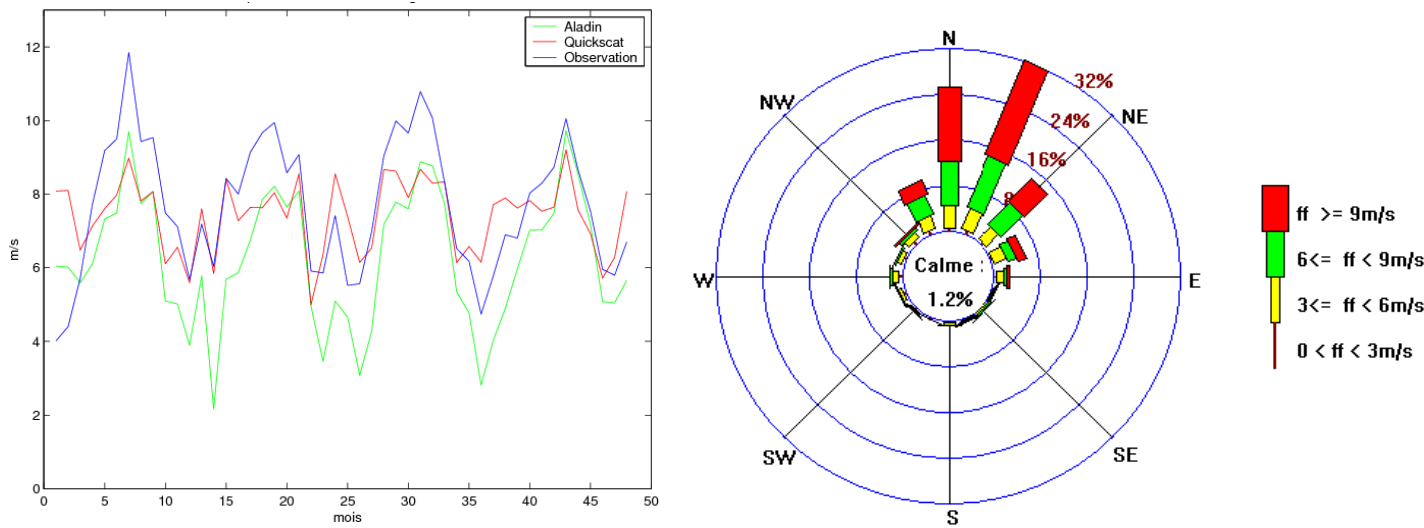

Fig. 6: (A) The ALADIN Wind in Situ Observation and Quikscat (Top), the Compass in-Situ Wind (Below) at Dakhla from 01/01/2003 to 31/12/2006. 

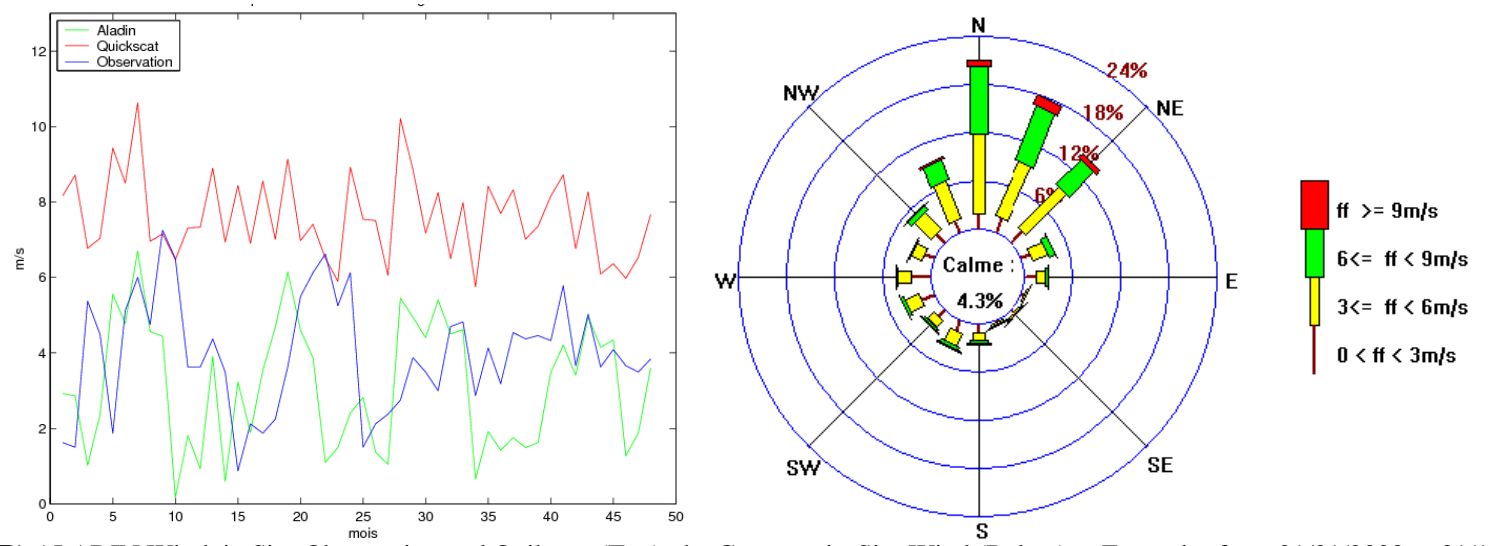

Fig. 6: (B) ALADIN Wind, in Situ Observation and Quikscat (Top), the Compass in-Situ Wind (Below) at Essaouira from 01/01/2003 to 31/12/2006.

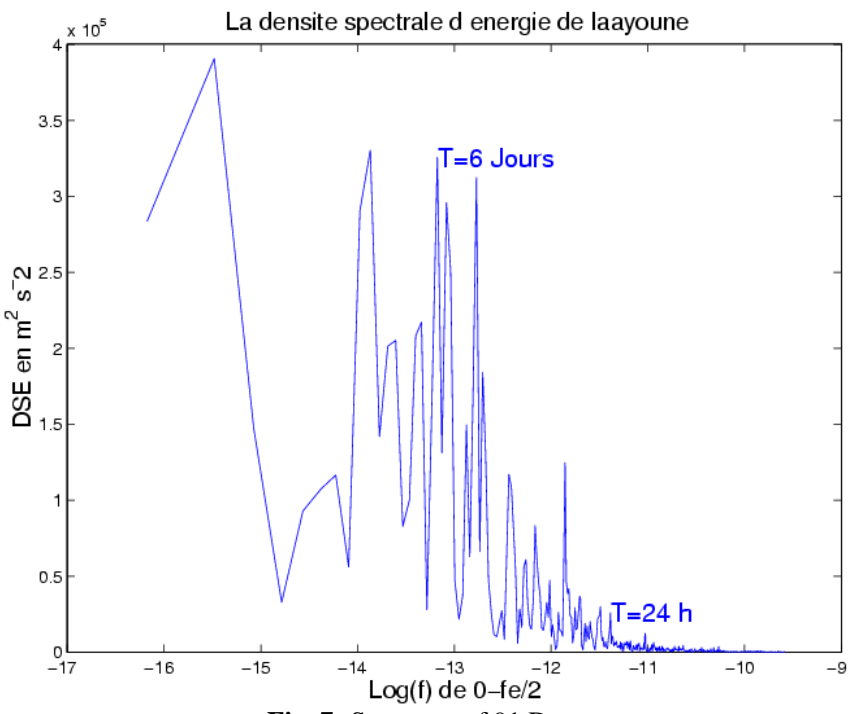

Fig. 7: Spectrum of 91 Days
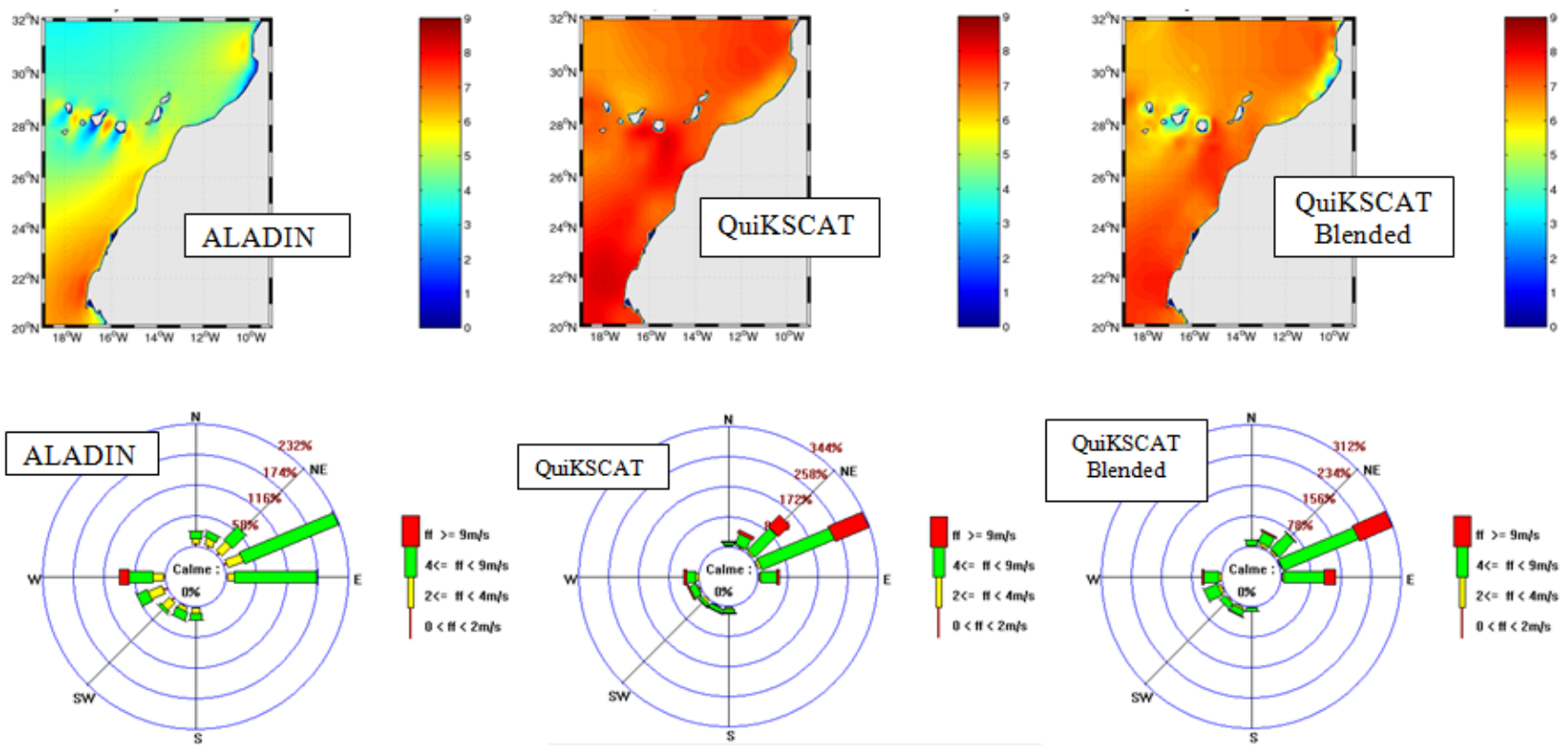

Fig. 8: Wind Speed and Direction from 01/01/2005 to 31/12/2006. 

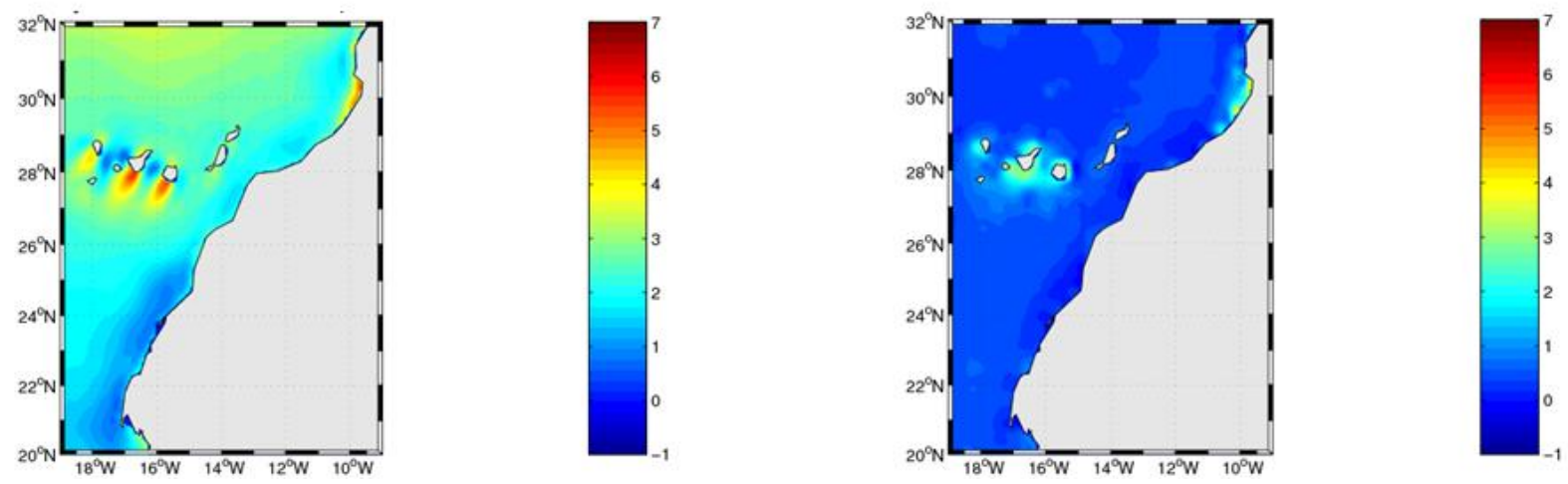

Fig. 9: The Difference of the Average Wind Quikscat-ALADIN (Left), Quikscat-QSCAT Blended (Right) from 01/01/2005 to 31/12/2006.

\section{Analyse of standard deviations of the differ- ences of wind components}

For a more detailed study, we proceeded to study the differences of wind components. From figure 10, we note that the seasonal variability of the difference in zonal and meridional wind between QuikSCAT and ALADIN is almost remarkable throughout the study area; it may be due to QuikSCAT data are extrapolated on the coast. The difference in seasonal variability is of the order of 1 $\mathrm{ms}^{-1}$ which shows that QuikSCAT is consistently high more than ALADIN and the winds are around the average. There is a strong variability localized between the Canary Islands of the order of 2 $\mathrm{m} / \mathrm{s}$ which may be due to the Venturi effect exerted by the coastal corridor on the wind when it passes between the islands. There is also variability in the northern area during the autumn and winter seasons with data from QuikSCAT and ALADIN explained by permanent winds nature during these seasons in this area. Significant variability is noted also during the same latest seasons confined to the coast and in the southern area during the summer season.

This variability of the difference of QuiKSCAT and ALADIN winds can also be explained by the extrapolation and resolution of scatterometer data in the coastal zone. Also, a significant variability recorded on the bay of Agadir and south of the Canary Islands with meridians winds, this variability is strongly linked to the expansion of wind due to the venturi effect exerted by the bay and the islands by adding acceleration to the wind.
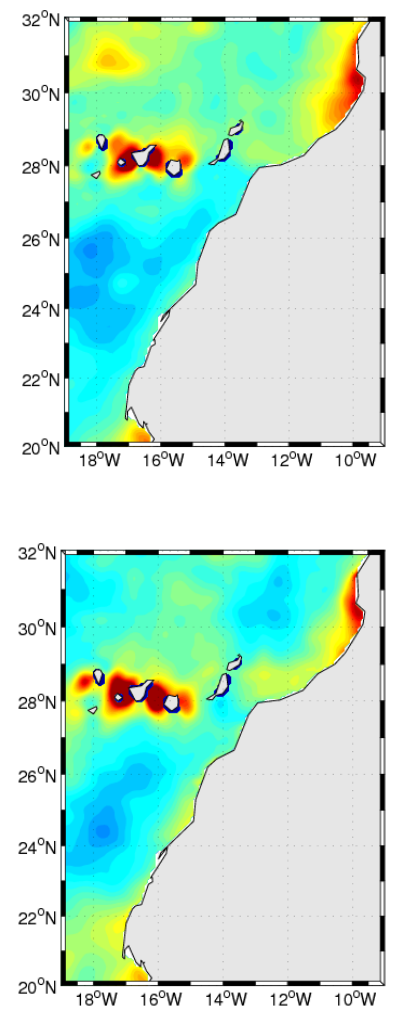
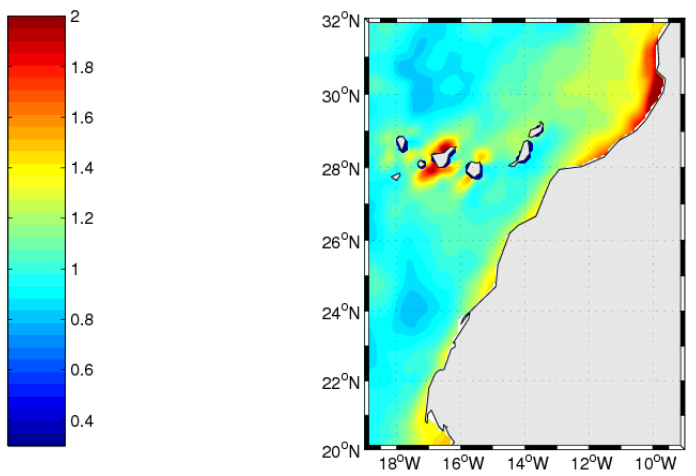

Fall Season (October, November and December)
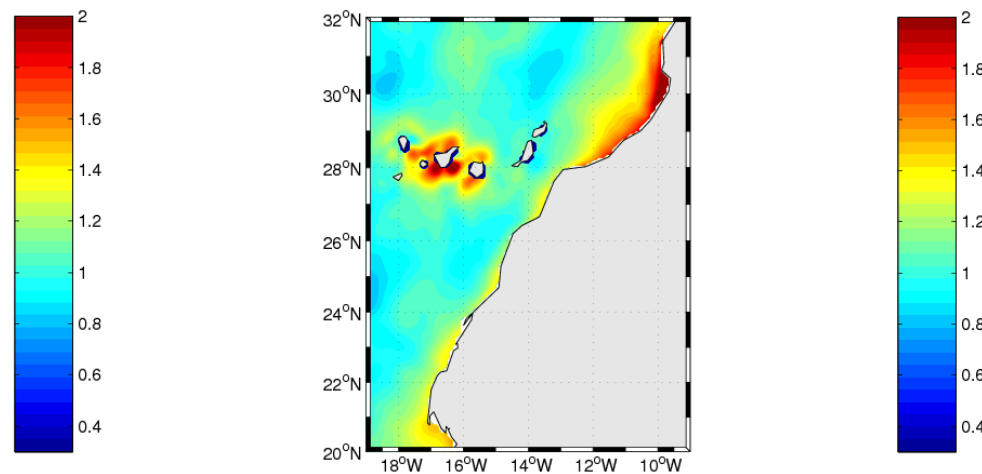

Winter Season (January, February and March) 

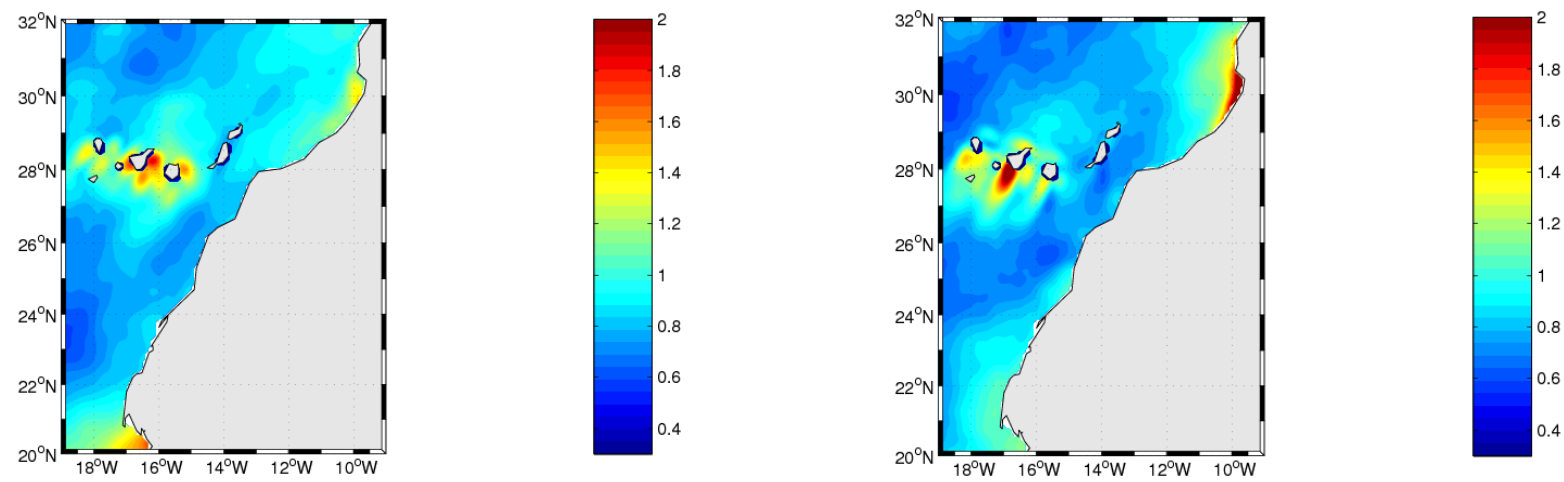

Spring Season (April, May and June)
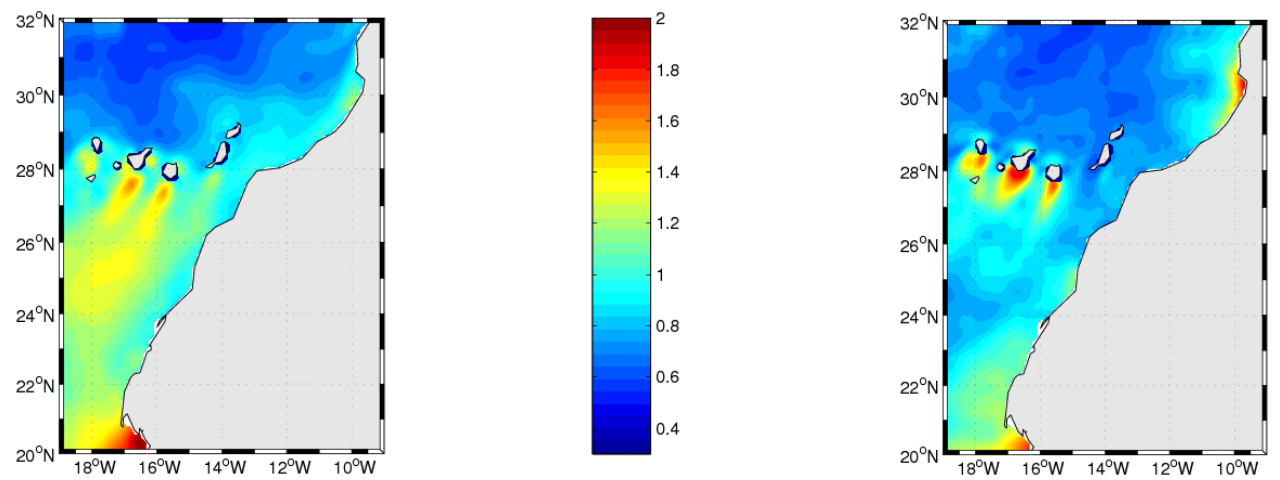

Summer Season (July, August and September)

Fig. 10: Standard Deviation of Zonal (Left) and Meridional (Right) Quikscat-ALADIN Wind.
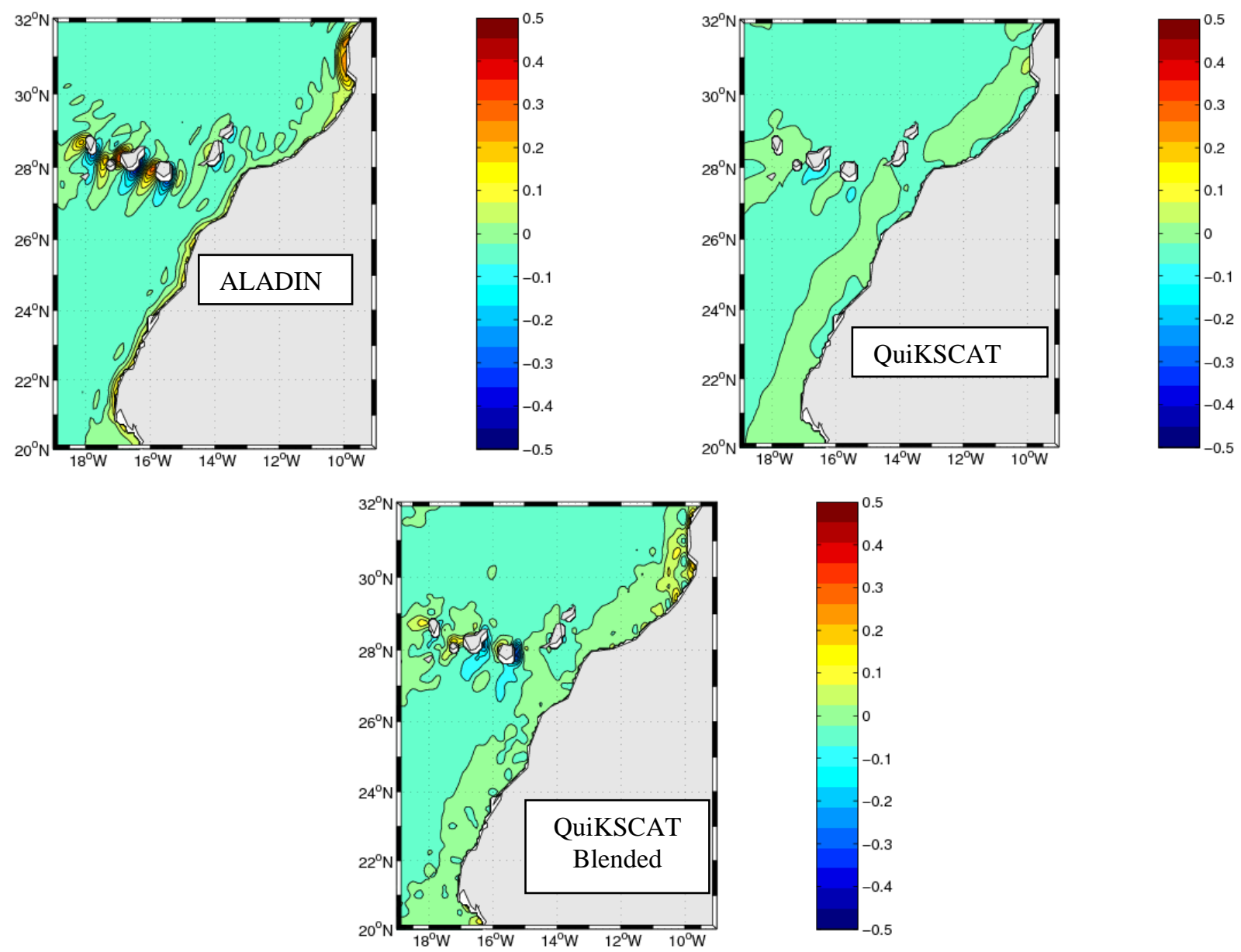

Fig. 11: The Curl Wind Stress from 01/01/2005 at 31/12/2006. 

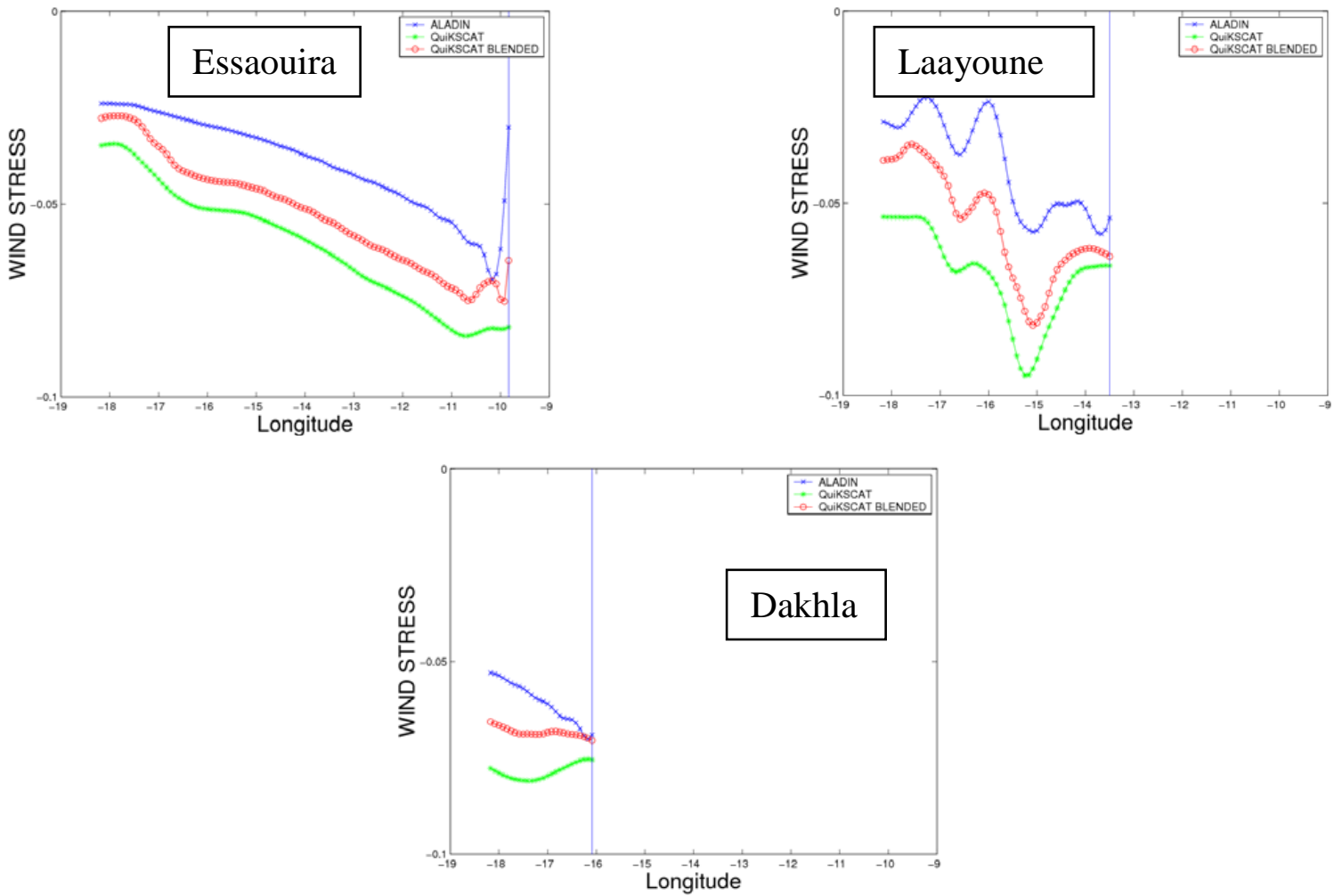

Fig. 12: The Evolution of Wind Stress from the Offshore to the Coast Over the Period 2005-2006

\section{Curl of wind stress and profile wind stress at the coast}

For a better understanding of the variability of wind at the coast, we propose to study the curl of the wind stress (Figure 11) and to establish the profile of the wind stress evolving offshore to the coast (Figure 12).

The outlines of the figure 11 from the three types of data show a positive maximum in the south of Essaouira, well confined to the coast, reaching $0.2 \mathrm{~Pa}(100 \mathrm{Km})^{-1}$, This maximum may be due to the acceleration of winds near Essaouira under effect of Hadid Cape. Also, it is notable that the curl from QuikSCAT and QuikSCAT Blended are quite smooth compared to ALADIN throughout the study area.

The curl from ALADIN and QuiKSCAT Blended provide more information inshore as against QuikSCAT; it highlights a meridian transport and flow along the bathymetry. This may be due to the absence of QuikSCAT data within $50 \mathrm{~km}\left(0.5^{\circ}\right)$ of coastline while data from ALADIN and QuikSCAT Blended cover the entire study area. It should be noted that the parameterization used for the product ALADIN is different from that used by both products QuiKSCAT. ALADIN model is using Large and Pond parameterization while Smith88 parameterization is used for QuikSCAT and QuikSCAT BLENDED.

For the illustration of the evolution of the wind stress at offshore to the coast, we studied the meridional wind stress in Essaouira, Laayoune and Dakhla points. Certainly, after the creation of the files of the wind forcing by ROMS_TOOLS package (http://www.brest.ird.fr/), we selected the neighboring points to the selected stations and then we made graphics representations (Figure 12). It is clearly noticeable that at latitude of Dakhla, the Aladin meridional wind stress declines toward the coast. The failing is also illustrated by the ALADIN model in Essaouira where the model simulates suitably the effect of Cap Hadid and Cap SIM. However, at Laayoune point, Aladin clearly indicates a decrease near the coast, which is not the case with QuikSCAT which remains stable in proximity of the coast. This is in contradiction with results obtained by Koraçin (Koraçin and al. 2003). Blended wind exhibits a similar tendency of Aladdin in
Essaouira. It should be noted that the pseudo sinusoid is shown in latitude of Laayoune while recording a general reduction of the power of wind from offshore to the coast; this illustration may be explained by the effect of the Canary Islands and the continent (Moujane A. et al, 2011).

\section{Discussion and conclusion}

This evaluation focused on the accuracy of the ALADIN model in terms of surface wind.

For the analysis of data from stations, results of the comparisons of wind speeds between QuikSCAT and Aladin data show high correlation coefficients ranging from 0.71 to 0.73 respectively in offshore and Dakhla. Furthermore, these correlations reached 0.84 between Aladin and in situ data in Dakhla. At Essaouira station was recorded the lowest correlation between in situ observations and model ALADIN (and QuikSCAT data). Possible reasons are the resolution of ALADIN model which is not sufficient to resolve the details of coastal topographic effects at this point, more than that, the satellite cannot perform measurements on the coast, in addition to the effects of reliefs of Hadid and SIM Capes.

For spatial analysis, QuikSCAT compared with Aladin and QuikSCAT BLENDED confirm a high correlation reaching 0.9 throughout the study area for the zonal and meridional wind component. Also, a high QuikSCAT variability was observed over ALADIN and Blended during all seasons, it is of the order of 2 ms-1 to 2.5 ms-1 with a small difference meridional wind which is of the order $0.5 \mathrm{~ms}-1$ on the study area, found mainly near the coast in the north of the area. A relief effect was noticed in the variability figures, which well shows the variability induced by the Caps, the bay and the islands on the wind and then the upwelling. In fact, the series of the average wind speed shows ALADIN could correctly reproduce the wind speed in areas of accented winds as well as areas of reduced winds. Some differences between simulations and satellite measurements can be attributed to the nature of the QuikSCAT data, which are daily, whereas the results of ALADIN model are a grid values for each 3 hours reduced to a daily average. The simulated winds comply well reasonably with winds of QuikSCAT and QuikSCAT BLENDED throughout the area of study, although there was a significant 
difference in the in situ and satellite observations. In addition, model resolution is $0.17^{\circ}$ whereas QUIKSCAT is only $0.5^{\circ}$ and resolution of QUIKSCAT BLENDED is $0.25^{\circ}$. Another reason consists on the limitations of the satellite measurement in Coasts. Finally, observations, measurements and simulations are clearly in spatial and temporal agreement in the South part of Morocco. They highlighted the effect of coastal topography on wind and the increase of this effect near the islands, bays and capes.

\section{Acknowledgements}

This research has been supported by the National Direction of Meteorology (DMN) of Morocco, IFREMER and by Ben M'Sick University. We would to thank colleagues from the DMN numerical forecasting staff and personnel of physics laboratory in University.

\section{References}

[1] Bentamy, A.; Croize-Fillon, D.; Queffeulou, P.; Liu, C.; Roquet, H. (2009): Ealuation of high-resolution surface wind products at global and regional scales, Journal of Operational Oceanography, Volume 2. Number 2, pp. 15-27(13)

[2] Bentamy A., H-L Ayina, P. Queffeulou, and D. Croize-Fillon; (2007): Improved Near Real Time Surface Wind Resolution over The Mediterranean Sea. Ocean Sci., 3, 259-271. http://dx.doi.org/10.5194/os-3259-2007.

[3] Blanke B., S. Speich, A. Bentamy, C. Roy, and B. Sow, 2005: Modeling the structure and variability of the southern Benguela upwelling using QuikSCAT wind forcing J. Geophys. Res., Vol. 110, No. C7, C07018 http://dx.doi.org/10.1029/2004JC002529.

[4] Bentamy A., K B. Katsaros, W. M. Drennan, E. B. Forde, (2002): Daily surface wind fields produced by merged satellite data. American Geophys. Union, Geophysical Monograph Series Vol. 127, 343-349.

[5] Bentamy, A, Y. Quilfen, and P. Flament (2002): Scatterometer wind fields: a new release over the decade 1991-2001. Canadian Journal of Remote Sensing, vol. 28, no 3, 424-430. http://dx.doi.org/10.5589/m02-041.

[6] Choa YI, Zhijin Li, John C. Kindle, Jeffrey D. Panduan, and Francisco P. Chavez, (2001): A high-resolution surface vector wind product for coastal oceans: Blending satellite scatterometer measurements with regional mesoscale atmospheric model simulations. Geophy. Res. Letters, 30(1), 1013, doi: 10.1029/2002GL015729, 2003 http://dx.doi.org/10.1029/2002GL015729.

[7] 7. Floors. R, Vincent. C.L., Gryning, S-E, Pena. An and. Batchvarova E, (2013): The wind profile in the coastal boundary layer: wind lidar measurements and numerical modelling, Kluwer Academic Publishers.

[8] Koraçin, D., C. E. Dorman, and E. P. Dever, (2004): Coastal perturbations of marine layer winds, wind stress, and wind stress curl along California and Baja California in June 1999. J. Phys. Ocean., 34, 1152-1173. http://dx.doi.org/10.1175/1520-0485 (2004)034<1152: CPOMWW>2.0.CO; 2.

[9] Large, W. G., and S. Pond, (1981): Open ocean momentum flux measurements in moderate to strong winds. J. Phys. Ocean, 11, 324 $481 \quad$ http://dx.doi.org/10.1175/1520-0485 (1981)011<0324: OOMFMI>2.0.CO; 2.

[10]10. Moujane A, Bentamy A, Chagdali M, Mordane S. (2011): Analysis of high spatial and temporal

[11]Surface winds from Aladin model and from remotely sensed data over the Canarian upwelling region. Accepté le 11 mars 2011, mis en ligne le 30 mai 2011 (C) Revue Télédétection, 2011, vol. 10, n 1, p. 11-22.

[12]Nelson, C. S. (1977), Wind stress and wind stress curl over the California current, Tech. Rep. NMFS SSRF-714, NOAA, and Silver Spring, Md.

[13]Open University, (2001): Oceanography Course Team. Elsevier, ISBN 0750652780, 9780750652780, $286 \mathrm{p}$.

[14]Smith S. D., (1988): Coefficients for sea surface wind stress, heat flux and wind profiles as a function of wind speed and temperature. J. Geophys. $\quad$ Res., $\quad 93, \quad 15467-15472$ http://dx.doi.org/10.1029/JC093iC12p15467.

[15]Winant, C. D., C. Dorman, C. Friehe, and R. Beardsley (1988), The marine layer off northern California: An example of supercritical channel flow, J. Atmos. Sci., 45, 3588 - 3605. http://dx.doi.org/10.1175/1520-0469 (1988)045<3588:TMLONC>2.0.CO; 2 